\title{
Taste-taste, odor-odor, and taste-odor mixtures: Greater suppression within than between modalities
}

\author{
DOUGLAS J. GILLAN \\ General Foods Technical Center, Tarrytown, New York
}

\begin{abstract}
Subjects judged the intensities of the component qualities of two taste stimuli [sucrose (S) and $\mathrm{NaCl}(\mathrm{N})$ ], two odor stimuli [citral (C) and anethole (A)], and the mixtures of these stimuli [taste-taste (SN), odor-odor (CA), and taste-odor (SC, NC, SA, and NA)]. The withinmodality mixtures, taste-taste and odor-odor, produced greater suppression of perceived intensity than did the between-modality mixtures, taste-odor. However, taste-odor mixtures also produced a significant amount of suppression of perceived intensity when compared with the individual taste and odor stimuli. The data are discussed with respect to peripheral and central mechanisms in mixture suppression.
\end{abstract}

There has been considerable interest in the effects of mixing taste stimuli on their perceived intensity; most research on taste mixtures has shown a decrease in the perceived intensity of the stimuli in a mixture in comparison with their separate presentation (e.g., Bartoshuk, 1975; Indow, 1969; Kamen, Pilgrim, Gutman, \& Kroll, 1961; Kiesow, 1896; Lawless, 1979; Moskowitz, 1972). This effect is known as mixture suppression.

In contrast to the large body of sensory research on taste mixtures, there has been less research on mixtures of tastes and odors (although see Murphy \& Cain, 1980, and Murphy, Cain, \& Bartoshuk, 1977). However, taste-odor mixtures should be of particular interest because most foods stimulate both the taste and the olfactory systems. That is to say, normal eating often involves temporally simultaneous tastes and odors.

Recent research from this laboratory on taste mixtures (Gillan, 1982) has implications for the effects of taste-odor mixtures on perceived intensity, as well. That research showed that mixture suppression was greater in two temporally and spatially contiguous stimuli than in two temporally contiguous but spatially separated taste stimuli. However, there was slight suppression with spatially separated tastes. These data suggested that a peripheral mechanism, such as spatial inhibition, plays a key role in taste

This research was supported by the General Foods Technical Center. The author thanks Adrienne Mikovits for her technical assistance and Dwight Riskey for helpful discussions. Special thanks are due William $S$. Cain for his advice about the odor stimuli and the procedures used here. Requests for reprints should be sent to the author at the General Foods Technical Center, T231, 555 South Broadway, Tarrytown, New York 10591. mixture suppression, producing the difference in suppression between spatially contiguous and spatially separated tastes. In addition, central mechanisms, such as selective attention, also apparently play a role in taste mixture suppression, producing the slight suppression observed with spatially separated tastes.

The hypothesis that both peripheral and central mechanisms are involved in mixture suppression suggests that the spatial separation between taste and olfactory receptors should result in less suppression in taste-odor mixtures than in within-modality (tastetaste and odor-odor) mixtures. In addition, the perceived intensity of the taste in the taste-odor mixture should be less than when it is presented alone; similarly, the odor should be perceived as less intense in the between-modality mixture than in isolation. Previous research has suggested that taste-odor mixtures produce slight suppression (Murphy \& Cain, 1980; Murphy et al., 1977). However, it was not possible to compare the response to the taste-odor mixtures with the responses to within-modality mixtures in those experiments because the subjects did not receive the within-modality mixtures. Because those comparisons are crucial to the hypothesis under consideration here, the subjects in the present experiment received two taste stimuli and two odor stimuli individually and in all possible two-stimuli mixtures.

\section{METHOD}

\section{Subjects and Stimull}

Three male and five female employees of the General Foods Technical Center volunteered to serve as subjects. The stimuli they received were $.35 \mathrm{M}$ sucrose (S), $.30 \mathrm{M} \mathrm{NaCl}(\mathrm{N}), 1 \%$ citral (C), $1 \%$ anethole (A), and various combinations of these individual stimuli. The tastants, sucrose and $\mathrm{NaCl}$, were dissolved in filtered tap water. The odorants, citral and anethole, were dissolved in odorless mineral oil (J. T. Baker heavy liquid petrolatum). In addition, on certain trials the taste stimulus was filtered 
tap water, and on other trials the odor stimulus was odorless mineral oil: those stimuli will be referred to as blanks (B).

The subjects sipped the tastants, $\mathrm{S}, \mathrm{N}$, and $\mathrm{SN}$ (a .36-M sucrose and $.30-\mathrm{M} \mathrm{NaCl}$ mixture), as well as the water blank on some trials, from polyethylene medicine cups. They sniffed the odor stimuli from cylindrical glass jars $(79 \mathrm{~mm}$ deep and with a $60-\mathrm{mm}$ diameter mouth). Inside each jar were two 10-ml Pyrex glass beakers, fixed to the bottom of the jar with odorless tape. Each beaker contained a cotton ball, approximately $.3 \mathrm{~g}$ in weight when dry, which was soaked in $2 \mathrm{ml}$ of either the mineral oil or a solution of mineral oil and odorant. On some trials, one beaker contained anethole and the other contained mineral oil; on a second type of trial, one beaker contained citral and the other contained mineral oil. On yet a third type of trial, one beaker contained anethole and the other contained citral. In other words, the odorants were mixed only in the vapor phase, not in the liquid phase. On still other trials, both beakers contained mineral oil. Different sniff jars were used for each trial.

\section{Procedure}

The subject received 10 trials in each of two sessions. The procedure used to present odor and/or taste stimuli on every trial was sip, sniff, and spit. At the start of a trial, a subject held a sip cup filled with $10 \mathrm{ml}$ of a taste solution (S, N, SN, or B) in one hand and a sniff jar containing the odorant $(C, A$, the CA mixture, or B) in the other hand. The subject sipped the entire contents of the sip cup and then immediately put the sniff jar to his or her nose and inhaled. The interval between sipping the taste solution and sniffing the odor solution was minimal, less than .5 sec. The subject tasted and sniffed the taste and odor stimuli, respectively, for approximately $3 \mathrm{sec}$. To end a trial, a subject removed the sniff cup from under his or her nose, and then spit out the taste solution and thoroughly rinsed his or her mouth. The procedure was selfpaced, but, in general, the intertrial interval was $30-60 \mathrm{sec}$. The sipand-sniff procedure insured the spatial separation of the odor and taste stimuli.

Various efforts were taken to reduce the citral and anethole odors in the air during the experiment. First, the sniff jars had tight screw-on lids; second, the subject received the trials in an enclosed area under a fan that removed odors from the room.

After ending a trial, each subject rated the intensities of the taste and odor qualities-bitter, salty, sour, sweet, lemon, and licoriceby magnitude estimation (e.g., Stevens, 1975). Prior to the first trial of each session, a trial with $S$ in the sip cup and $B$ in the sniff jar was given; the subject was told that the sweetness of that stimulus was 100 and to judge the magnitude of all other stimuli in relation to that standard. This pretrial was not included in the data analysis, since subjects did not freely respond on it.

There were three types of trials: individual stimulus trials, within-modality mixture trials, and between-modality mixture trials. Two of the individual stimulus trials involved a taste stimulus and two involved an odor stimulus. On trials with an individual taste stimulus, both of the beakers in the sniff jar contained mineral oil; therefore, these trials were S-B and N-B. On trials with an odor stimulus, the sip cup contained water; these trials were B$\mathrm{C}$ and B-A. On one of the within-modality mixture trials, the sip cup contained water and the sniff jar contained the CA mixture (BCA). On the other within-modality mixture trial, the sip cup contained SN and the sniff jar had only odorless mineral oil (SN-B). The four between-modality mixtures involved every combination of taste stimulus in the sip cup and odor stimulus in the sniff cup-S-C, S-A, N-C, and N-A. Although the between-modality mixtures did not involve spatial mixing of the two stimuli, the stimuli were temporally simultaneous; consequently, the tasteodor compound stimuli in this experiment are referred to as mixtures.

\section{RESULTS}

In the present experiment, the subjects judged the perceived intensities of four individual stimuli, $\mathbf{S}, \mathbf{N}$, $C$, and $A$, as well as all possible within-modality [taste-taste (SN) and odor-odor (CA)] and betweenmodality [taste-odor (SC, SA, NC, and NA)] mixtures. The mean judgments of the sweetness, saltiness, lemon odor, and licorice odor are shown in Table 1 for the relevant stimuli. (The only stimuli that the subjects judged to be appreciably sweet were those containing sucrose, to be salty were those with $\mathrm{NaCl}$, to be lemon were those with citral, and to be licorice were those with anethole. No stimuli were judged to be appreciably bitter or sour.)

The hypothesis that central mechanisms are involved in mixture suppression predicts that the individual stimuli (N-B, S-B, B-C, and B-A) should be perceived to be more intense in the relevant taste and odor qualities than the taste-odor mixtures (N-C, N$\mathrm{A}, \mathrm{S}-\mathrm{C}$, and $\mathrm{S}-\mathrm{A}$ ); the hypothesis that peripheral mechanisms are involved in mixture suppression predicts that the taste-odor mixtures should be perceived to be more intense in the relevant attributes than the taste-taste (SN-B) or odor-odor (B-CA) mixtures. The general pattern of results shown in Table 1 supports these two predictions: individual stimuli are more intense than taste-odor mixtures, which are more intense than within-modality mixtures.

In general, statistical analyses are consistent with a visual inspection of Table 1. First, the 10 stimuli differed significantly in sweetness, saltiness, lemon, and licorice $[F s(9,150)=62.7,39.0,24.7$, and 30.4 , respectively, all ps $<.001]$. Additional paired comparisons used Duncan's multiple-range test $(p<.05)$ (e.g., see Keppel, 1973). The paired comparisons for sweetness showed that: (1) all stimuli with sucrose

Table 1

Mean Perceived Intensity of Relevant Taste and Odor Qualities of Sucrose (S-B), $\mathrm{NaCl}$ (N-B), Anethole (B-A), Citral (B-C), Taste-Taste (SN-B) and Odor-Odor (B-CA) Mixtures, and Taste-Odor Mix tures (S-C, S-A, N-C, and N-A)

Quality

\begin{tabular}{|c|c|c|c|c|c|c|c|}
\hline \multicolumn{2}{|c|}{ Sweetness } & \multicolumn{2}{|c|}{ Saltiness } & \multicolumn{2}{|c|}{ Licorice } & \multicolumn{2}{|c|}{ Lemon } \\
\hline Stimulus & $\begin{array}{l}\text { Perceived } \\
\text { Intensity }\end{array}$ & Stimulus & $\begin{array}{l}\text { Perceived } \\
\text { Intensity }\end{array}$ & Stimulus & $\begin{array}{l}\text { Perceived } \\
\text { Intensity }\end{array}$ & Stimulus & $\begin{array}{l}\text { Perceived } \\
\text { Intensity }\end{array}$ \\
\hline S-B & 120.0 & $N-B$ & 101.6 & B-A & 103.1 & $B-C$ & 114.1 \\
\hline S-A & 86.2 & $\mathrm{~N}-\mathrm{A}$ & 82.5 & $\mathrm{~N}-\mathrm{A}$ & 62.8 & $\mathrm{~N}-\mathrm{C}$ & 60.6 \\
\hline$S-C$ & 77.2 & $\mathrm{~N}-\mathrm{C}$ & 71.6 & S-A & 57.5 & $S-C$ & 60.0 \\
\hline SN-B & 59.4 & SN-B & 49.4 & B-CA & 40.0 & $\mathrm{~B}-\mathrm{CA}$ & 39.4 \\
\hline
\end{tabular}


were sweeter than those without; (2) sucrose alone was the sweetest stimulus; and (3) the sucrose-odor mixtures were sweeter than the sucrose- $\mathrm{NaCl}$ mixture. An identical pattern was evident for saltiness: (1) $\mathrm{NaCl}$ alone was the saltiest stimulus; (2) the $\mathrm{NaCl}$-odor mixtures were saltier than the sucrose$\mathrm{NaCl}$ mixture; and (3) the stimuli with $\mathrm{NaCl}$ were saltier than those without. Similarly, (1) the lemon odor was strongest for citral alone, (2) was stronger for the taste-citral mixtures than for the citralanethole mixture, and (3) was stronger for stimuli with citral than for those without. The pattern of results for the licorice odor differed slightly from those above: (1) the perceived licorice odor was strongest for anethole alone; $(2)$ the $\mathrm{NaCl}$-anethole mixture was stronger in licorice odor than was the citralanethole mixture; but (3) the strength of the licorice odor of the sucrose-anethole mixture was not significantly different from either the $\mathrm{NaCl}$-anethole mixture or the citral-anethole mixture.

\section{DISCUSSION}

The present data showing substantial suppression with taste-taste and odor-odor mixtures and lesser but consistent suppression with taste-odor mixtures are generally compatible with previous experiments that have looked separately at each of these types of mixtures (e.g., Bartoshuk, 1975, for taste-taste mixtures; Cain \& Drexler, 1974, for odor-odor mixtures; and Murphy \& Cain, 1980, for taste-odor mixtures). However, the crucial feature of the design of this experiment is that the subjects received all three types of mixtures in the same experiment. Consequently, the data could show that the same odor stimulus that strongly suppressed the perception of another odor had less effect on a taste stimulus. Likewise, the taste stimuli that strongly suppressed concurrent taste perception had a weaker effect on concurrent odor perception. These findings show the modality-specific nature of mixture suppression.

As detailed above, the hypothesis that peripheral mechanisms are involved in mixture suppression anticipated that mixture suppression should be modality specific because of the stronger peripheral interactions (e.g., spatial inhibition) within modalities than between modalities. The present data suggest that peripheral mechanisms play a role in both the suppression that occurs with taste-taste mixtures and the suppression that occurs with odor-odor mixtures. It will probably be most profitable to assume initially that the peripheral mechanisms in these two chemical senses work in the same way.

The hypothesis that central mechanisms play a role in mixture suppression anticipated the suppression observed with taste-odor mixtures. It is noteworthy that research on taste adaptation (Gillan, Note 1) and on odor adaptation (Cain, 1977) also indicates that central mechanisms are involved in taste and odor adaptation, respectively. Because both adaptation and mixture suppression result in a decrease in perceived intensity, it is tempting to hypothesize that the same central mechanisms affect perception in these two situations.

\section{REFERENCE NOTE}

1. Gillan, D. J. Evidence for central and peripheral mechanisins in taste adaptation. Manuscript submitted for publication, 1983.

\section{REFERENCES}

Bartoshux, L. M. Taste mixtures: Is mixture suppression related to compression? Physiology \& Behavior, 1975, 14, 643-649.

CAIN, W. S. Bilateral interaction in olfaction. Nature, 1977, 268, 50-52.

Cain, W. S., \& Drexler, M. Scope and evaluation of odor counteraction and masking. Annals of the New York Academy of Sciences, 1974, 237, 427-439.

GiLlan, D. Mixture suppression: The effect of spatial separation between sucrose and $\mathrm{NaCl}$. Perception \& Psychophysics, 1982, 32, 504-510.

InDOw, T. An application of the $\tau$ scale of taste: Interactions among the four qualities of taste. Perception \& Psychophysics, $1969,5,347-351$.

Kamen, J. M., Pilorim, F. L., Gutman, N. J., \& Kroll, B. J. Interaction of suprathreshold taste stimuli. Journal of Experimental Psychology, 1961, 62, 348-356.

KEPPEL, G. Design and Analysis: $A$ researcher's handbook. Englewood Cliffs, N.J: Prentice-Hall, 1973.

Kiesow, F. Beitrage zur physiologischen Psychologie des Geschmackssines. Philosophische Studien, 1896, 12, 255-278.

LAwLESS, H. T. Evidence for neural inhibition in bitter-sweet taste mixtures. Journal of Comparative and Physiological Psychology, 1979, 93, 538-547.

Mosxowitz, H. R. Perceptual changes in taste mixtures. Perception \& Psychophysics, 1972, 11, 257-262.

MURPhy, C., \& CaIN, W. S. Taste and olfaction: Independence vs. interaction. Physiology \& Behavior, 1980, 24, 601-605.

Murphy, C., CAin, W. S., \& Bartoshuk, L. M. Mutual action of taste and olfaction. Sensory Processes, 1977, 1, $204-211$.

Stevens, S. S. Psychophysics. New York: Wiley, 1975.

(Manuscript received April 6, 1982; revision accepted for publication November 24, 1982.) 